U.S. Department of Commerce, Bureau of Standards

RESEARCH PAPER RP663

Part of Bureau of Standards Journal of Research, vol. 12, March 1934

\title{
PORTABLE DETECTOR FOR RADIUM
}

\author{
By L. F. Curtiss
}

ABSTRACT

Apparatus, making use of a simple 2-stage vacuum-tube amplifier with small ionization chamber, for detecting lost radium preparations is described. Indications of the approach of the chamber to a preparation appear on a small microammeter mounted in the case of the instrument. With a sensitivity such that $10 \mathrm{mg}$ of radium produces a deflection of 10 microamperes at a distance of 1 meter, a lost preparation of this size can be located in a large room filled with filing cases, apparatus, etc., in less than 10 minutes. Small B batteries and large flashlight cells are used to energize the dry-cell tubes so that the instrument is entirely self-contained and thus can be used in any location. The total weight is 18 pounds.

I. Introduction

II. Amplifying circuit. 380

III. Description of battery case and ionization chamber

IV. Tests of arrangement

\section{INTRODUCTION}

Hospitals and other institutions using a number of radium preparations ranging from 5 to $25 \mathrm{mg}$ are occasionally confronted with the necessity of finding one when lost or misplaced. These preparations are usually in the form of needles between 1 and 2 millimeters in diameter and 15 to 30 millimeters long. When lost, they are often very difficult to find except by means of their radiation. The goldleaf electroscope is about the only instrument which has been available up to the present time for this purpose. Although it is simple and can be made easily portable, its use in locating a radium preparation, under the usual conditions met with, is very tedious. To survey completely an ordinary room may require several hours, since the electroscope must be read every few feet, and the charging and reading the rate of fall of the leaf requires about 5 minutes for each position. When it comes to searching out of doors, in garbage cans, sewers, and piles of refuse, as is frequently necessary, a gold-leaf electroscope is far from satisfactory. It occurred to the writer that an easily portable 
instrument could be built which would show a steady deflection on a meter, increasing in magnitude as the lost preparation is approached. The time required for a search would thus be greatly reduced and such an instrument could be used effectively by persons without special training in its use, which is not true of the efficient use of the electroscope. This paper describes an instrument which appears to fulfill the requirements, and under actual test has shown that it is possible by its use to locate preparations very quickly.

\section{AMPLIFYING CIRCUIT}

The resistance-coupled, two-stage, vacuum-tube circuit used is fundamentally the same as that described by the author elsewhere, ${ }^{1}$ modified slightly to conform to the requirements of this special application. The wiring diagram for this circuit is shown in figure 1. The 32 tube used in the first stage is mounted in a metal shielding tube with the ionization chamber. The control grid of this tube is connected directly to the central collecting rod of the ionization chamber. This rod is also connected to the metal shield through a resistor, $R_{1}$, of about $10^{9} \mathrm{ohms}$ resistance. ${ }^{2}$ The leads for the filament, plate, screen grid, and ionization chamber are brought through a flexible metal tube to the metal battery case in which a 30 tube used

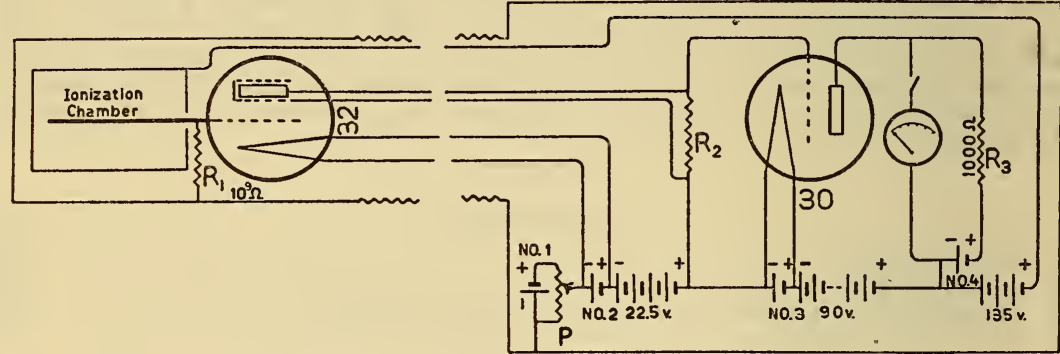

FIGURE 1.-Wiring diagram of amplifier.

for the second stage of the amplifier is located, with all batteries for the amplifier. The two stages are coupled through $R_{2}$ (a 0.5 megohm resistor), and the output of the last stage is passed through a microammeter shunted by a dry cell, no. 4 in the figure, and a 1,000-ohm resistor $R_{3}$, as shown in the diagram. The output current is indirectly controlled by the potentiometer, $\mathrm{P}$, connected with the filament circuit of the first stage. With this arrangement the microammeter will show zero current when adjusted by turning the knob of the potentiometer, $\mathrm{P}$ - this being the only adjustment required to make the instrument ready for use. The microammeter will then continue to show zero current until radiation affects the ionozation chamber.

\section{DESCRIPTION OF BATTERY CASE AND IONIZATION CHAMBER}

As indicated by the wiring diagram, the instrument consists of two parts, an ionization chamber connected by a flexible metal tube to a metal battery case. A cross section, to scale, of the aluminum

1 Curtiss, L. F., B.S. Jour. Research, vol. 10 (RP 550), p. 585, 1933.

2 Lacquer-coated graphite resistors described by the author in Rev. Sci. Inst., vol. 4, no. 12, December 1933, have been found to be satisfactory. 
B.S. Journal of Research, RP663

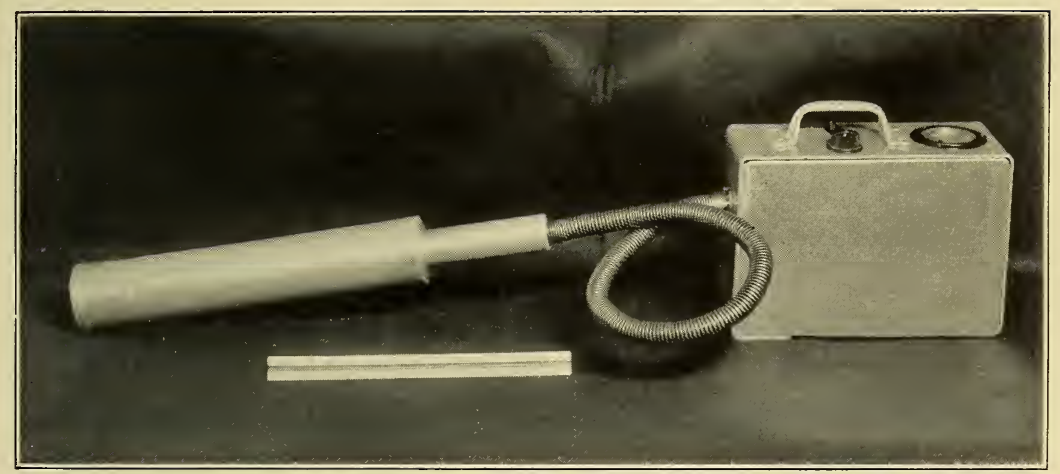

FIGURE 4.-Photograph of assembled instrument. 
ionization chamber is shown in figure $2 .^{3}$ The method of mounting the 32 tube and high-resistance resistor in the metal shielding tube is also shown.

The adopted arrangement permits a very short lead from the collector rod of the ionization chamber to the control grid of the 32 tube, and thus simplifies the problem of electrostatic shielding for this part of the circuit-the only part particularly sensitive to external disturbances.

The battery case, also of aluminum, is shown with one side removed (fig. 3). This drawing, also to scale, shows the position of batteries and other accessories, making evident its compactness. The cells (1.5 volt flashlight cells), chosen for minimum weight, are provided with a spring mounting so that they may be slipped into position and then immediately taken out at the completion of a search - to prolong their life. This, of course, eliminates the necessity for filament switches. The switch shown in the top view is in series with the microammeter which it is intended to protect during the time when the set is momentarily out of use and the dry cells still in position.

A photograph of the actual instrument is shown in figure 4, with a 12 -inch scale, which gives an idea of the size. The total weight is

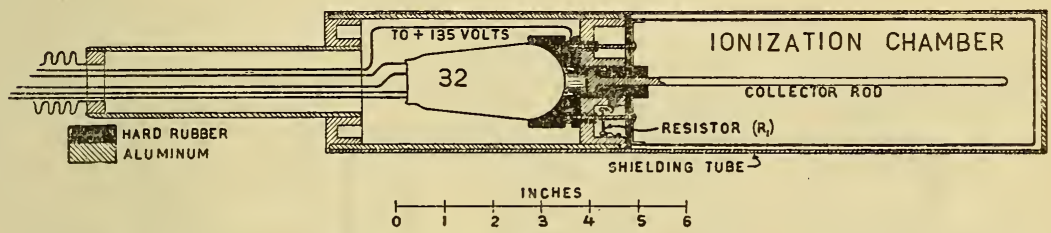

FIGURE 2.-Cross section of ionization chamber.

less than 18 pounds. When in use, the battery case is carried in one hand and the ionization chamber in the other. Sufficient flexibility is afforded by the corrugated-metal tube so that the ionization chamber can be pointed in any direction relative to the case.

\section{TESTS OF ARRANGEMENT}

To obtain some evidence regarding the effectiveness of the device, representative trials were made in which $10 \mathrm{mg}$ of radium was concealed from view in relatively inaccessible locations unknown to the operator. He was then given the information which might be expected to be available when a preparation is actually lost. First, several trials were made with preparations concealed in backs of filing cases, under trash baskets, etc., in a large room. The only information given was that the preparation was in that room. The average time required to locate the radium was about 5 minutes.

A further trial was made out of doors. A 10-mg preparation was concealed in the roots of grass along the curbing of a roadway connecting two buildings about 500 yards apart. The operator was then

\footnotetext{
${ }^{3}$ All metal parts are made of aluminum to reduce weight.
} 
conducted over the route taken by the person who had "lost" the preparation. One trip over the route with the instrument, requiring less than 5 minutes, resulted in recovery of the hidden sample. In

\section{TOP VIEW}
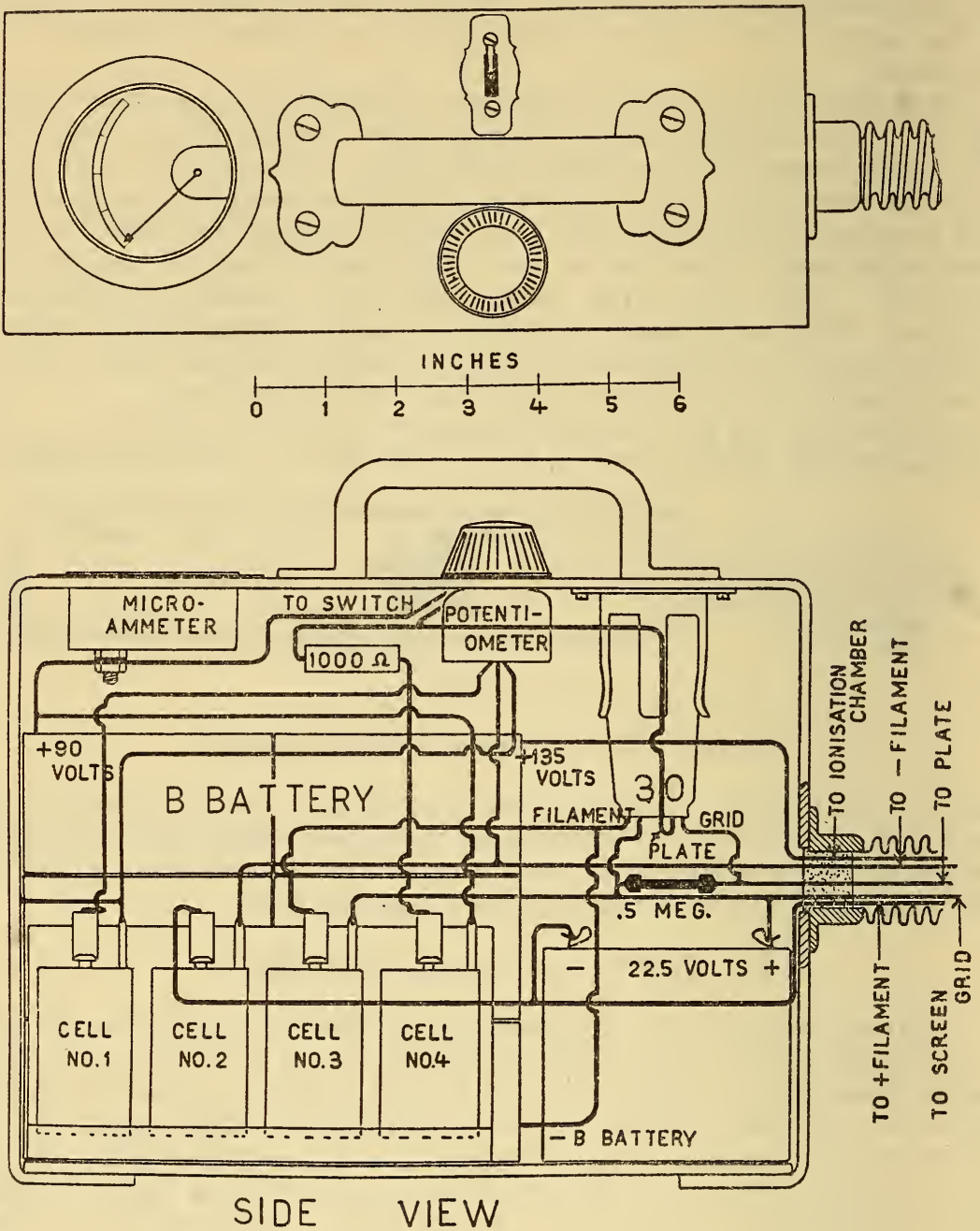

FIGURE 3.-Drawing showing interior of battery case.

all tests of this kind, the arrangement proved to have many advantages over the electroscope for this purpose.

The writer wishes to express his indebtedness to B. W. Brown for help in making the apparatus and A. V. Astin for aid in designing the device.

Washington, December 14, 1933. 